\title{
Turbulent Supersonic/Hypersonic Heating Correlations for Open and Closed Cavities
}

\author{
Joel L. Everhart ${ }^{*}$ and Francis A. Greene* \\ NASA Langley Research Center, Hampton, VA, 23681
}

\begin{abstract}
Supersonic/hypersonic laminar heating correlations that were developed for damageassessment analysis of atmospheric re-entry vehicles have been modified and extended to cover fully-turbulent conditions over rectangular cavity geometries that are aligned with the local velocity. Turbulent boundary layer properties were computationally determined and used to develop the cavity geometry parametrics and to correlate experimental closed cavity heating data to yield new relationships for the floor-averaged and centerline endwall peakheating augmentation. With the form of the closed-cavity correlations established, historical data were used to develop new correlations for turbulent open-cavity heating.
\end{abstract}

\section{Nomenclature}

a, b correlation curve fit coefficients, see Eq. 2

BF Bump Factor

h heat transfer coefficient, $h=q /\left(\mathrm{H}_{a w}-\mathrm{H}_{\mathrm{w}}\right),\left(\mathrm{lbm} / \mathrm{ft}^{2} / \mathrm{s}\right)$

$\mathrm{L}, \mathrm{W}, \mathrm{H}$ cavity length, width, and depth (in)

LCL/UCL lower/upper confidence limit

LPL/UPL lower/upper prediction limit

M Mach number

$\mathrm{M}_{\mathrm{e}} \quad$ boundary layer edge Mach number at the cavity entrance

$\mathrm{R}^{2} \quad$ Linear Correlation Coefficient

$\mathrm{Re} \quad$ unit Reynolds number $(1 / \mathrm{ft})$

$\mathrm{Re}_{\theta} \quad$ momentum thickness Reynolds number

$\mathrm{X}, \mathrm{Y} \quad$ correlation parameters, see Eq. 2.

$\mathrm{x} \quad$ axial distance from model leading edge (in)

y spanwise distance from model centerline (in)

$\mathrm{z} \quad$ distance normal to $\mathrm{x}-\mathrm{y}$ plane (in)

$\alpha \quad$ angle-of-attack (deg)

$\alpha, \beta, \sigma, \tau \quad$ Bump Factor correlation coefficients, see Eq. 1

$\delta \quad$ boundary layer thickness (in)

$\theta \quad$ boundary layer momentum thickness (in)

Subscripts

AVG average value in cavity

FR stagnation point conditions from Fay-Riddell calculation for a hemisphere

LAM laminar

MAX maximum value on cavity centerline immediately downstream of endwall

TURB turbulent

$\infty \quad$ freestream static conditions

\footnotetext{
${ }^{*}$ Senior Research Engineer, Aerothermodynamics Branch, and AIAA Associate Fellow

* Senior Research Engineer, Aerothermodynamics Branch, and AIAA Senior Member
} 


\section{Introduction}

The August 2003 Final Report of the Space Shuttle Columbia Accident Investigation Board ${ }^{1}$ (CAIB) recommended the development of improved damage assessment models for application to future flights, primarily for laminar flow conditions. In response, the Orbiter Entry Aeroheating Panel at the NASA Johnson Space Center established the Cavity Heating Team to develop the Cavity Heating Tool (CHT). This tool defines the heating augmentation to the vehicle outer mold lines caused by impact damage that does not penetrate the vehicle aluminum substructure. A survey of the cavity heating literature conducted for CHT development revealed that much general information was available on cavity flow physics and heating; however, information required to address Orbiterspecific damage was very sparse. For example, there was no information regarding the real-cavity effects of random geometry, cross-flow, or pressure gradient. This sparseness led to an extensive series of supersonic/hypersonic idealized-cavity-flow experiments by Everhart, et al. ${ }^{2-6}$ that were conducted in the conventional 20-Inch Mach 6 and 31-Inch Mach 10 Wind Tunnels at the NASA Langley Research Center. The idealized cavity geometries were rectangular boxes that were easily defined by depth $(\mathrm{H})$, width $(\mathrm{W})$, and length $(\mathrm{L})$, and scaled with the cavityentrance boundary layer thickness $(\delta)$. Heating was measured using global phosphor thermography methods. The reference documents contain an in-depth presentation of the literature survey; and, they describe the multitude of idealized cavity geometries tested to establish the effects of length, width, depth, entry/exit/sidewall angles, orientation, surface curvature, and the fluid dynamic effects of Mach number, Reynolds number, and boundary layer thickness. Preliminary analysis of these data enabled the development of the assessment methods that form the foundation of the CHT as reported by Anderson, et al. ${ }^{7}$

A discussion of the cavity flow physics and a more refined analysis of the laminar-entry heating augmentation or bump factor (BF) was presented in Reference 8 for open-flow (short) cavities where the flow skips over the cavity and for closed-flow (long) cavities where the flow enters the cavity and impinges on the floor. Open cavities have a nominal $\mathrm{L} / \mathrm{H}<10$, while closed cavities are nominally $\mathrm{L} / \mathrm{H}>14$. The transitional-cavity region between $\mathrm{L} / \mathrm{H}=10$ and 14 may be unsteady as the flow oscillates back and forth between the two steady flow regimes. A combined singlecurve parametric variation for the floor-averaged $\mathrm{BF}$ and centerline endwall maximum $\mathrm{BF}$ was derived, as was a model of the heating-wake decay downstream of the cavity. Additionally, uncertainty limits on the correlation curve coefficients and prediction limits about the correlation curves were also provided.

A limited number of closed-flow turbulent test cases were obtained as a part of the Mach 6 cavity heating experiments to baseline heating levels and variations (Ref. 3). Using this data, the above-cited laminar correlations have now been extended to include turbulent boundary layer conditions. The turbulent data were originally reduced and reported using laminar computational solutions for entry reference conditions because turbulent solutions were unavailable. Turbulent solutions have since been developed, and the turbulent data have been re-reduced with these new entry conditions. The first task in this paper is to present a sample of the re-reduced turbulent data. Next, the laminar correlation parameters will be tested to determine their applicability to characterize closed-cavity turbulent heating variations. Coefficient values in the parameters will then be adjusted to minimize turbulent correlation uncertainties. Finally, using this functional relationship as a guide, correlations will be developed for turbulent openflow cavities using archival data obtained from the literature.

\section{Experimental Methods}

This section presents a brief discussion of the experimental methods for the data obtained in Test 6888 (denoted T6888). The test facility is first discussed, followed by a description of the models and cavity design, and an overview of the phosphor thermography data system used to acquire the global heating measurements. Finally, the data reduction and presentation parameters are described.

\section{A. Facility}

The NASA Langley 20-Inch Mach 6 Tunnel was used to develop the turbulent cavity-heating database. This conventional, perfect-gas blowdown facility uses air as a test medium. It is described in detail in Micol. ${ }^{9}$ Flow properties were determined using the GASPROPS code developed by Hollis. ${ }^{10 .}$

\section{B. Models}

A schematic showing the model coordinate system orientation is presented in Figure 1. The $\mathrm{x}$ axis is measure down the length of the model and the $\mathrm{z}$ axis is measure normal to the surface. Initially, the origin is at the model leading edge; it is transferred to the cavity leading edge for data analysis. A strut-mounted 10 -inch-wide by 28 -inchlong steel flat-plate model having a blunted leading edge with a radius of 0.125 inches was used for experiments 
(see Figure 2). The blunt nose model provides edge Mach numbers of approximately 2.9 to 3 (see Ref. 2) at zero incidence as required to match Orbiter flight surface conditions. The model includes an upstream insert region where boundary layer trips can be installed. Boundary layer trip hardware and tripping methods developed by Berry, et. al. ${ }^{11,12}$ were used to ensure turbulent flow over the model. Using Berry's specification, the height of the trip, $\mathrm{k}$, is determined from $\mathrm{k} / \delta=0.6$ for the present flow conditions. Off-design test conditions were examined to ensure fully tripped turbulent conditions. A discussion of the boundary layer trips and the baseline heating data are presented in Ref. 3. The model also includes a 4-inch wide by 18 -inch long aft region starting 7.5 inches from the nose for test articles. A representative example of the T6888 cavity inserts (see Ref. 3) is shown in Figure 3. They were fabricated using ceramic casting methods as described in Buck, et al. ${ }^{13,14}$ After fabrication, the cavity models were coated with a nominal $27 \mu \mathrm{m}$ thick mixture of phosphors suspended in a silica-based colloidal binder ${ }^{15}$ and sent to quality assurance for measurement and application of small circular locating markers, known as fiducial marks. Cavity size parameters and location on the insert plate are given in Table 1.

\section{Cavity Designs and Test Conditions}

Impact-induced cavities must be geometrically and fluid-dynamically scaled for damage assessment modeling. For the Shuttle Orbiter, a maximum cavity depth constraint can be established based on the thickness of the thermal protection system tiles. Because of the launch configuration, impact damage on the forward portion of the vehicle is likely to be deep and short, in contrast to long, shallow grazing damage that is more likely on the aft portion of the vehicle. Parametric variations used to establish the cavity-heating database were guided by these general considerations.

Typical surface flow conditions for the windward surface of the Shuttle Orbiter were obtained from Campbell, et al. ${ }^{16}$ to establish the parameter variations at the cavity entrance, $\left(\mathrm{M}_{\mathrm{e}}, \mathrm{Re}_{\theta}, \delta\right)_{\text {Flight }}$. Centerline test article surface conditions were determined for the tunnel freestream conditions from two-dimensional centerline contour simulations of the baseline geometry using the LAURA code. ${ }^{17,18}$ The range of the computationally determined $\left(\mathrm{M}_{\mathrm{e}}, \mathrm{Re}_{\theta}\right)_{\text {Tunnel }}$ conditions was matched to flight. The boundary layer thickness ratio $\left(\delta_{\text {Tunnel }} / \delta_{\text {Flight }}\right)$ was used to scale flight damage scenarios to tunnel scale. Cavity conditions $\left(\mathrm{M}_{\mathrm{e}}, \mathrm{Re}_{\theta}, \delta\right)_{\text {Tunnel }}$ were taken from the computational solutions at the cavity entrance.

All turbulent-entry data were acquired using closed (long) baseline geometries, each with a flat bottom and rectangular planform and cross section. Tripped turbulent flow was developed over the model surface as discussed in Ref. 3. Specifics of the flight-to-tunnel scaling, cavities, and their designs are included in the database publications by Everhart, et al., using methods and hardware developed by Berry, et al. to ensure fully-turbulent flow.

\section{Phosphor Thermography Technique}

Global surface heating distributions were calculated using the two-color, relative-intensity phosphor thermography method. ${ }^{15}$ This is the standard technique for obtaining aeroheating data in NASA Langley's hypersonic wind tunnels, and it can be used to identify the surface heating effects of complex three-dimensional flow phenomena, which are difficult to examine using conventional discrete-sensor methods. With this method, ceramic wind tunnel models are coated with phosphor crystals that fluoresce in the red and green regions of the visible light spectrum when illuminated by ultraviolet (UV) light. The phosphor-coated model is exposed to the heated flow during a wind tunnel run, and the resulting changes in fluorescence intensity of the model are recorded and digitized. The surface temperature distributions are determined from the fluorescence intensities through prior calibrations, reduced to surface heating distributions, and analyzed using the IHEAT ${ }^{15}$ code, which implements onedimensional, semi-infinite-solid heat conduction theory. These distributions may be mapped onto a 3-dimensional $\mathrm{CAD}$ representation of the test article using the MAP3D ${ }^{15}$ code.

\section{E. Data Reduction}

Global mappings of the surface heating were converted to a cavity-based reference system by translating the origin from the leading edge of the model to the leading edge center of each cavity. They were then scaled using the cavity depth and the boundary layer thickness at the cavity leading edge to yield a scaled-geometry cavity of depth $\mathrm{H} / \delta$, width $\mathrm{W} / \mathrm{H}$, and length $\mathrm{L} / \mathrm{H}$.

Local heating augmentation or bump factor (BF) was used to assess the effect of the cavity on the undisturbed environment. Bump Factor is defined as the local heating $\left(\mathrm{h}_{\text {local }}\right)$ normalized by an averaged reference heating $\left(\mathrm{h}_{\mathrm{AVG}}\right)$, yielding $\mathrm{BF}=\mathrm{h}_{\text {local }} / \mathrm{h}_{\mathrm{AVG}}$. For analysis consistency, $\mathrm{h}_{\mathrm{AVG}}$ is computed from the measured data, in a scaledspace region ahead of each cavity across the cavity width over the length $-3 \leq \mathrm{x} / \mathrm{H} \leq-1$. In this format, $\mathrm{BF}=1$ 
becomes the nominal, fully developed, undisturbed condition for a flat plate. This location also avoids a potential bias caused by an expansion-induced heating peak upstream of the cavity leading edge. Two metrics, $\mathrm{BF}_{\mathrm{AVG}}$ and $\mathrm{BF}_{\mathrm{MAX}}$, are used to characterize the cavity heating. $\mathrm{BF}_{\mathrm{AVG}}$ was determined by averaging all imaged data inside the entire cavity. Only a small number of non-floor pixels were present because the upstream endwall was not visible in the camera imaging and only 2-3 pixels were visible in any longitudinal linecut on the downstream cavity endwall. Likewise, only one of the sidewalls was imaged and, typically, only 1-2 pixels were visible in any spanwise linecut. This area averaging greatly reduced noise in the data caused by the low temperatures experienced on the cavity floor for laminar flow conditions. $\mathrm{BF}_{\mathrm{MAX}}$ was determined as the maximum centerline value; this value was typically located immediately downstream of the cavity endwall.

\section{Computational Simulation of Baseline Model Surface Flow}

Boundary layer edge properties were computed using the LAURA ${ }^{18,19}$ (Langley Aerothermodynamic Upwind Relaxation Algorithm) code. LAURA is a computational fluid dynamics (CFD) tool specialized for hypersonic reentry physics and chemistry. In the past, the LAURA code has been applied and validated for a range of vehicle shapes and flow conditions including the Shuttle Orbiter laminar aerothermodynamic flight data ${ }^{20}$, blunt planetary configurations, ${ }^{21,22}$ and slender lifting bodies. ${ }^{23}$ The code is a three-dimensional upwind finite-volume solver for the inviscid Euler equations, thin-layer Navier-Stokes, or full Navier-Stokes governing equations. Roe-averaging ${ }^{24}$ with Harten's entropy fix ${ }^{25}$ and Yee's Symmetric Total Variation Diminishing (TVD) limiter ${ }^{26}$ is used to formulate the inviscid fluxes, while a second order scheme solves the viscous fluxes. Point-relaxation is used to begin the iterative solution while a line relaxation approach is invoked to complete the integration in time to steady state.

The Navier-Stokes equations were solved in simulating the turbulent flow over a flat-plate at ground-based test conditions in conjunction with a perfect gas air thermodynamic model. For this work, it was sufficient to start the turbulent flow at the plate leading edge and it was modeled using the Cebeci-Smith algebraic turbulence model. ${ }^{27} \mathrm{~A}$ sample of the turbulent heating prediction is compared with experimental measurements for Run 31 in Figure 4a $\left(\mathrm{M}_{\mathrm{e}}=2.93, \mathrm{Re}_{\theta}=150\right)$. Corresponding longitudinal predictions for the $\mathrm{M}_{\mathrm{e}}, \mathrm{Re}_{\theta}$, and $\delta$, are presented in Figure $4 \mathrm{~b}$. Laminar solutions are also presented in the figures for comparison.

\section{Test Data and Parameter Space}

The turbulent-run test matrix is presented in Table 1, along with the scaled geometry and the $\mathrm{BF}_{\mathrm{AVG}}$ and $\mathrm{BF}_{\mathrm{MAX}}$ values for each set of conditions. Typically, a cavity length sweep is presented at nearly constant values of $M_{e}, \operatorname{Re}_{\theta}$ and $\mathrm{H} / \delta$. Turbulent bump factor image data are presented in Figure 5 and Figure 6 . These demonstrate how the flow physics can change with cavity length. In contrast to the laminar data (see Ref. 8), significant vortex interactions occur on the sides at the top of the turbulent cavity as the flow strongly expands into the cavity, carrying high temperature fluid. The images show the significant increase in floor heating on the center and in the corner where vortex scrubbing elevates the temperatures. The complexity of the flow field is further evidenced by the occurrence of multiple heating peaks on the downstream endwall under some conditions, for example see Figure 5. In fact, the peak heating may not occur on the centerline because of this flow characteristic.

Linecut plots of the BF distributions are presented in each of the image figures for illustration purposes only. These are taken longitudinally along the cavity centerline, spanwise at the cavity entrance, spanwise near the midcavity location, and spanwise at the cavity exit. The spanwise spread and the longitudinal decay of the cavity wake are also highlighted as flow recovers to an undisturbed state.

\section{Summary of Laminar Bump Factor Correlations}

Previously developed laminar correlations are presented here in preparation for the turbulent development. Everhart ${ }^{8}$ graphically demonstrated that neither $\mathrm{BF}_{\mathrm{AVG}}$ nor $\mathrm{BF}_{\mathrm{MAX}}$ could be correlated with the individual primary test variables (e.g. $M_{e}, R_{\theta}, R_{\theta} / M_{e}, L / H, H / \delta, L / \delta$ ) for laminar flow. Accordingly, the test variables were combined into laminar correlation parameters to describe the variation of heating over a wide range of conditions for both open and closed cavity flow physics using aggregate and separate Mach 6 and Mach 10 data. These correlation parameters are given by 


$$
\begin{aligned}
& X=\ln \left[M_{e}^{\sigma} \operatorname{Re}_{\theta}^{\tau}\left(\frac{L}{\delta}\right)\right] \\
& Y=\ln \left[\left(\frac{H}{\delta}\right)^{\alpha}\left(1+\frac{L}{H}\right)^{\beta} B F\right]
\end{aligned}
$$

For later comparison with the turbulent results, the laminar Mach 6 power coefficients are presented in Table 2.

The correlation parameters for $\mathrm{BF}_{\mathrm{AVG}}$ and $\mathrm{BF}_{\mathrm{MAX}}$ were developed using the Mach 6 baseline, rectangular cavity data from T6888. These parameters were then input to the commercially available SYSTAT TableCurve $2 D$ program to establish the mathematical relationships for the heating variations. The coefficients $a$ and $b$ in the linear (in transformed log-log space) correlation curve

$$
\mathrm{Y}=\mathrm{a}+\mathrm{bX}
$$

were determined by the program. Output from the program included Confidence Limits on the curve coefficients and the Linear Correlation Coefficient, $\mathrm{R}^{2}$, as statistical measures of the goodness-of-fit to the data. Confidence Limits are a measure of the uncertainty in the average value of a coefficient drawn from an existing population. The Linear Correlation Coefficient measures how well the data fit a linear mathematical model, with $\mathrm{R}^{2}=1$ providing a perfect fit. Prediction Limits measure the ability of the curve to estimate the value of a future observation obtained from the population. By statistical necessity, Prediction Limits must be wider than Confidence Limits to capture the additional uncertainty carried by the new data. A discussion of these statistical concepts is provided in Morrison ${ }^{28}$.

The Mach 6 laminar correlation curves and the Mach 6 data are presented in Figure 7 for reference. Open cavity data are represented by open symbols and the closed cavity data are represented by closed symbols. All of the data scatter uniformly about the correlation curve within the bounds of the $99 \%$ Prediction Limits. Because these data were acquired on a laminar low-temperature flat plate, the scatter band is wider than would be anticipated for a higher temperature turbulent flow. Therefore, it is anticipated that the prediction intervals for the turbulent correlations will be narrower. For clarity, only the laminar curves will be presented for comparison in subsequent figures.

\section{Turbulent Closed-Cavity Heating Correlations}

Beginning with the laminar relationships presented in the previous section, the first step in analyzing the turbulent data was to assess whether Eq. 1 and parameter powers in Table 2 yield any significant correlation of $\mathrm{BF}_{\mathrm{AVG}}$ and $\mathrm{BF}_{\mathrm{MAX}}$. Direct, unadjusted application of these expressions is provided in Figure 8, revealing welldefined offset variations, but with significant scatter that is functionally related to the cavity depth. Therefore, the values of the laminar powers provided in Table 2 must be adjusted to remove the depth effect for the turbulent conditions.

New turbulent power coefficients were developed following the process developed in Ref. 8. The laminar powers were iteratively changed to maximize the value of the Correlation Coefficient, $\mathrm{R}^{2}$. These new turbulent values are presented in Table 4 and the results of the modifications are shown in Figure 9. Significant improvements in the linearity are provided with the adjusted values that are indicative of the reduced scatter provided by the correlation. The $\mathrm{R}^{2}$ for $\mathrm{BF}_{\mathrm{AVG}}$ has increased from 0.950 to 0.993 ; the $\mathrm{R}^{2}$ for $\mathrm{BF}_{\mathrm{MAX}}$ has increased from 0.930 to 0.988. The Degrees of Freedom Adjusted $\mathrm{R}^{2}$ values are 0.993 for $\mathrm{BF}_{\mathrm{AVG}}$ and 0.987 for $\mathrm{BF}_{\mathrm{MAX}}$, all measures implying a high degree of linear modeling.

Convergence to a local minimum/maximum is a concern in all optimization problems. A correlation development question was whether a single set of correlation parameters could be developed to describe both laminar and turbulent conditions. As a check on the minimization process, the laminar data were tested against the turbulent correlations. The turbulent parameters did describe the gross behavior of the laminar heating, but did so poorly. Therefore, separate closed-cavity correlations of the heating are required for the two boundary layer states.

As before, correlation curve coefficient values were developed and they are provided in Table 5. Also provided are the $99 \%$ Upper Confidence Limits on the curve fit, and the 99\% Upper Prediction Limits. Interestingly, the turbulent correlations are nearly parallel to the laminar correlations, as determined by both visual observation in Figure 9 and by comparison of the slopes (b coefficient) given in Table 3 with those in Table 5. The turbulent $99 \%$ uncertainty bounds are narrower than those developed for the laminar correlations because the higher heating reduces the uncertainty in the individual measurements. Fewer data are available over a narrower test space resulting 
in a broadening of the uncertainty at the extents of the turbulent correlation curve. Therefore, the uncertainty was estimated using a linear approximation between the end points.

Final expressions for the correlations are obtained by substituting equations (1) into Eq. (2), yielding

$$
\left(\frac{H}{\delta}\right)^{\alpha}\left(1+\frac{L}{H}\right)^{\beta} B F=e^{a}\left[M_{e}^{\sigma} \operatorname{Re}_{\theta}^{\tau}\left(\frac{L}{\delta}\right)\right]^{b}
$$

where the values of the powers $\alpha, \beta, \sigma$, and $\tau$ are obtained from Table 4 , and the a and b coefficients are obtained from Table 5 .

A relationship for the Bump Factor uncertainty, $\triangle \mathrm{BF} / \mathrm{BF}$, can be obtained by subtracting the linear relationship for the Correlation Curve from the linear relationship from the Upper Prediction Limit. This is given by

$$
\frac{\Delta B F}{B F}=e^{\left(a_{U P L}-a\right)}\left[M_{e}^{\sigma} \operatorname{Re}_{\theta}^{\tau}\left(\frac{L}{\delta}\right)\right]^{\left(b_{b P L}-b\right)}-1
$$

where $\Delta \mathrm{BF}=\mathrm{BF}_{\mathrm{UPL}}-\mathrm{BF}$ and, as above, the coefficients are obtained from Table 5. Uncertainties in the turbulent closed-cavity correlations are given as

$$
\left(\frac{\Delta B F}{B F}\right)_{A V G, T u r b}=1.3457\left[M_{e}^{0.25} \operatorname{Re}_{\theta}^{0.35}\left(\frac{L}{\delta}\right)\right]^{0.0028}-1=0.35
$$

and

$$
\left(\frac{\Delta B F}{B F}\right)_{M A X, T u r b}=1.6991\left[M_{e}^{0.80} \operatorname{Re}_{\theta}^{0.40}\left(\frac{L}{\delta}\right)\right]^{0.0094}-1=0.70
$$

Reflecting the lower temperature measurements, larger uncertainties were present for the laminar correlations developed in Ref. 8. For comparison, they are

$$
\left(\frac{\Delta B F}{B F}\right)_{A V G, L a m}=0.75
$$

and

$$
\left(\frac{\Delta B F}{B F}\right)_{M A X, L a m}=1.28
$$

\section{Turbulent Open-Cavity Heating Correlations}

Fully turbulent closed-cavity heating data were not discovered in the open literature; however, several sources of turbulent open-cavity data with sufficient analysis information for obtaining cavity-floor averages were available. Because all of the archival data were acquired using discrete sensors, measurements in the vicinity of the endwall top edge were difficult to obtain, allowing only extrapolated peak values containing large uncertainties. Accordingly, only correlations using the floor averages (an integral process with less inherent error) were attempted. The data sources where the boundary layer entering the cavity is turbulent are Charwat ${ }^{29,30}$, Emery ${ }^{31}$, Netterfield ${ }^{32}$, and Thomann ${ }^{33}$. These data were acquired on the wind tunnel floor and on an axisymmetric cone. Data acquired by $\mathrm{Hahn}^{34}$ (axisymmetric cylinder) and $\mathrm{Nestler}^{35}$ (flat plate) have transitional boundary layers entering the cavity. According to Nestler, the heating augmentation for transitional flow will be the same as that for turbulent flow over a separated cavity. This important hypothesis for cavity design and impact damage assessment will be demonstrated as erroneous.

These archival data represent an extremely wide range of turbulent flow and geometric conditions that are tabulated in Table 6 and plotted as $\mathrm{BF}_{\mathrm{AVG}}$ versus $\mathrm{L} / \delta$ in Figure 10. Cavity-entry Mach number varies from 1.8 to 9 ; momentum thickness Reynolds number varies from 2098 to 32288; depth $\mathrm{H} / \delta$ varies from 0.44 to 4.17; and length 
$\mathrm{L} / \delta$ varies from 0.33 to 44 . All of the cavities have a rectangular (or nearly rectangular) profile geometry with a width $\mathrm{W} / \mathrm{H}$ that varies from 1.25 for the three dimensional cases to infinity for the axisymmetric cases. In many cases the required boundary layer parameters were unavailable in the reports. Referencing White ${ }^{36}$, estimates of the turbulent thicknesses were obtained from

$$
\frac{\delta}{\mathrm{x}}=0.37 \mathrm{Re}_{s}^{-1 / 5} \text { and } \frac{\theta}{\mathrm{x}}=0.036 \mathrm{Re}_{s}^{-1 / 5}
$$

where $\operatorname{Re}_{S}$ is the Reynolds number based on boundary layer run length. Combining Eqs. (9) yields

$$
\frac{\theta}{\delta}=0.097
$$

Equation 10 was used to determine the momentum thickness Reynolds number where required. Average floorheating data was obtained by integrating cavity-heating distributions when not provided directly in report figures.

An initial attempt at correlating the turbulent open cavity $\mathrm{BF}_{\mathrm{AVG}}$ using the turbulent closed cavity correlation is shown in Figure 11. These comparisons were developed using Eqs. (1), and powers from Table 4. While the turbulent closed-cavity correlation collapses each individual data set, the different sets are unacceptably separated. Unlike the single-curve correlation provided for laminar open and closed cavities in Ref. 8, two distinct correlations are required for turbulent open and closed cavities. A successful direct application of the laminar correlation powers (Table 2) to the turbulent open cavity data is presented in Figure 12. No attempt at further scatter-reduction via modification of the laminar powers was attempted. The implication of this collapse is that cavity heating is a vortex and gradient driven problem where the flow gradients for laminar open and closed cavities are relatively benign, as they are for open turbulent cavities. Thus, the flows scale similarly, providing a single set of correlation powers. A definitive statement regarding the behavior of $\mathrm{BF}_{\mathrm{MAX}}$ cannot be made without appropriate data; however, similar behavior is anticipated. Closed turbulent cavities provide three distinct internal flow fields that develop severe turning gradients. These differences result in much higher heating levels and greater variability along the cavity floor, and they are reflected in the powers in the scaling parameters and in the turbulent curve-fit slopes. With the correct turbulent scaling defined, it is now observationally clear that transitional-entry cavities are outliers, and the data should be excluded.

Finally, Figure 13 presents the turbulent open-cavity correlation curves. The powers and curve coefficients are presented in Table 7 and Table 8, respectively. As with the turbulent closed cavity, curve-fit coefficients, Confidence Limits, and Prediction Limits were determined at the $99 \%$ level of uncertainty using the SYSTAT TableCurve $2 D$ program. Analytical expressions for the open-cavity uncertainties can be obtained following the procedure presented in Eqns. (3) through (6).

\section{Concluding Remarks}

A massive cavity-heating database was generated to support tool development for impact damage assessment of re-entry vehicle thermal protection systems. These data were previously documented and they formed the basis of the current laminar analysis methods that are incorporated into the Cavity Heating Tool (Version 3). These laminar cavity data were recently re-analyzed and new correlations with quantifiable uncertainty levels were developed and reported for the floor-averaged bump factor (or heating augmentation) and the maximum endwall bump factor.

Included in the dataset were turbulent cases for comparison with laminar cavity heating and for evaluation of the existing turbulent analysis methodologies. These turbulent data have now been reduced using new turbulent simulations of the base model (no cavity) flow field. Application of the laminar-cavity heating correlations to the turbulent closed-cavity data captured the variations of the cavity-floor-averaged heating and the maximum heating on the cavity endwall; however, data scatter was larger than desired. New turbulent coefficients were successfully derived, and they are very descriptive of cavity heating under common surface flow and geometric variations. Archival turbulent open-cavity data covering an extremely wide range of flow conditions and geometry have been retrieved from the literature and they were successfully correlated. Current and future vehicle programs should benefit from their application to impact-damage assessment and to vehicle risk reduction efforts during design. 


\section{References}

\footnotetext{
${ }^{1}$ Report of the Columbia Accident Investigation Board, Volume 1, National Aeronautics and Space Administration, August 2003.
}

${ }^{2}$ Everhart, Joel L., Berger, Karen T., Bey, Kim S., Merski, N. Ronald, and Wood, William A., "Cavity Heating Experiments Supporting Shuttle Columbia Accident Investigation,” NASA TM 2006-214528, 2006.

${ }^{3}$ Everhart, Joel L., Berger, Karen T., Brauckmann, Gregory J, Merski, N. Ronald, and Wood, William A., "Parametric Cavity Heating Experiments Supporting Shuttle Orbiter Return To Flight,” NASA JSC EG-SS-06-04, 2007.

${ }^{4}$ Everhart, Joel L., Alter, Stephen J., Merski, N. Ronald, Wood, William A., and Prabhu, Ramadas K., "Pressure Gradient Effects on Hypersonic Cavity Flow Heating," AIAA 2006-0185, Presented at 44th AIAA Aerospace Sciences Meeting and Exhibit, Reno, NV, January 9-12, 2006.

${ }^{5}$ Everhart, Joel L., Berger, Karen T., Merski, N. Ronald, Wood, William A., Hollingsworth, Kevin E., Hyatt, Andrew J., and Prabhu, Ramadas K., "Aero-Heating of Shallow Cavities in Hypersonic Freestream Flow,” NASA JSC EG-SS-06-07, 2007.

${ }^{6}$ Everhart, Joel L., Hollingsworth, Kevin E., Erickson, David W., Merski, N. Ronald, and Prabhu, Ramadas K., "Real-Cavity Heating Experiments Supporting Shuttle Orbiter Return To Flight,” NASA JSC EG-SS-07-01, February 2007.

${ }^{7}$ Anderson, Brian, Hyatt, Jay, Wang, K.C., Everhart, Joel, Greene, Frank, Pulsonetti, Maria, Wood, Bill, Bourland, Gary, and Cassady, Amy, “ The Cavity Heating Tool,” Boeing Technical Memorandum ATA-AH-TM-2005-079, The Boeing Company, NASA Space Systems, Houston, TX, Dec. 7, 2005.

${ }^{8}$ Everhart, Joel L., "Supersonic/Hypersonic Laminar Heating Correlations for Rectangular and Impact-Induced Open and Closed Cavities," AIAA 2008-1283, Presented at 46th AIAA Aerospace Sciences Meeting and Exhibit, Reno, NV, January 7-10, 2008.

9 Micol, J.R.: "Hypersonic Aerodynamic/Aerothermodynamic Testing Capabilities at Langley Research Center: Aerothermodynamic Facilities Complex," AIAA Paper 95-2107, June 1995.

${ }^{10}$ Hollis, B.R., "Real-Gas Flow Properties for NASA Langley Research Center Aerothermodynamic Facilities Complex Wind Tunnels," NASA CR 4755, September 1996.

${ }^{11}$ Berry, S.A., Difulvio, Michael, and Kowalkowski, Matthew K., "Forced Boundary-Layer Transition on X-43 (Hyper-X) in NASA LaRC 20-Inch Mach 6 Air Tunnel.” NASA TM-2000-210316, Aug.2000.

${ }^{12}$ Berry, S.A., Auslender, A.H., Dilley, A.D., and Calleja, J.J., "Hypersonic Boundary-Layer Trip Development for HyperX,” Journal of Spacecraft and Rockets, Volume 38, Number 6, pp. 853-864, 2001.

${ }^{13}$ Buck, G.M., and Vasques, P., "An Investment Ceramic Slip-Casting Technique for Net-Form, Precision, Detailed Casting of Ceramic Models," U.S. Patent 5,266,252, November 1993.

${ }^{14}$ Buck, G.M., Powers, M.A., Nevins, S.C., Griffith, M.S., Verneris, P.H., and Wainwright, G.A., "Rapid Fabrication of Flat Plate Cavity Phosphor Thermography Test Models for Shuttle Return-to-Flight Aero-Heating," NASA TM 2006-214508.

${ }^{15}$ Merski, N.R., "An Improved Two-Color Relative-Intensity Phosphor Thermography Method for Hypersonic Wind Tunnel Aeroheating Measurements,” NASA CDTP-1017, February 2001.

${ }^{16}$ Campbell, Charles H., Wang, K. C., An, Michael Y., Tam, Luen T., Bouslog, Stanley A., "Orbiter Boundary-Layer Working Group, Numerical Flow Field Analysis Data,” JSC-26816, December, 1994.

${ }^{17}$ Gnoffo, P.A., Gupta, R.N., and Shinn, J.L., "Conservation Equations and Physical Models for Hypersonic Air Flows in Thermal and Chemical Nonequilibrium,” NASA TP 2867, February 1989.

${ }^{18}$ Gnoffo, P.A., An Upwind-Biased, Point-Implicit Relaxation Algorithm for Viscous, Compressible Perfect Gas Flows," NASA TP 2953, February 1990.

${ }^{19}$ Gnoffo, P. A., Gupta, R. N., and Shinn, J., "Conservation Equations and Physical Models for Hypersonic Air Flows in Thermal and Chemical Nonequilibrium," NASA TP 2867, 1989.

${ }^{20}$ Gnoffo, P. A., and Weilmuenster, K. J., "Multiblock Analysis for Shuttle Orbiter Re-Entry Heating from Mach 24 to Mach 12," AIAA Paper 93-2813, July 1993.

${ }^{21}$ Gnoffo, P. A., Weilmuenster, K. J., Braun, R. D., and Cruz, C. I., "Influence of Sonic-Line Location on Mars Pathfinder Probe Aerothermodynamics," Journal of Spacecraft and Rockets, Vol. 33, No. 2, 1996, pp.169-177.

${ }^{22}$ Gnoffo, P. A., Braun, R. D., Weilmuenster, K. J., Mitcheltree, R. A., Engelund, W. C., and Powell, R. W., "Prediction and Validation of Mars Pathfinder Hypersonic Aerodynamic Database," Journal of Spacecraft and Rockets, Vol. 36, No. 3, 1999, pp. 367-373.

${ }^{23}$ Thompson, R. A., Gnoffo, P. A., "Application of the LAURA Code for Slender-Vehicle Aerothermodynamics," Journal of Spacecraft and Rockets, Vol. 29, No. 1, 1992, pp. 16-23.

${ }^{24}$ Roe, P. L., "Approximate Riemann Solvers, Parameter Vectors and Difference Schemes," Journal of Computational Physics, Vol. 43, No. 2, 1981, pp. 357-372.

${ }^{25}$ Harten, A., "High Resolution Schemes for Hyperbolic Conservation Laws," Journal of Computational Physics, Vol. 49 , No. 3, 1983, pp. 357-393.

${ }^{26}$ Yee, H. C., "On Symmetric and Upwind TVD Schemes,” NASA TM 88325, 1990.

${ }^{27}$ Cebeci, T. "Behavior of Turbulent Flow near a Porous Wall with Pressure Gradient," AIAA Journal, Vol. 8, No. 12, December 1970, pp. 2152-2156.

${ }^{28}$ Morrison, Donald F., “Applied Linear Statistical Methods,” Prentice-Hall, Inc., Englewood Cliffs, New Jersey, 1983. 
${ }^{29}$ Charwat, A.F., Roos, J.N., Dewey, C.F., Jr., and Hitz, J.A., “An Investigation of Separated Flows - Part I, The Pressure Field," Journal of Aerospace Sciences, Vol. 28, No. 6, June 1961, pp. 457-470.

${ }^{30}$ Charwat, A.F., Dewey, C.F., Roos, J.N., and Hitz, J.A., "An Investigation of Separated Flows - Part II, Flow in the Cavity and Heat Transfer," Journal of Aerospace Sciences, Vol. 28, No. 7, pp. 513-527, July 1961.

31 Emery, A.F.: "Recompression Step Heat Transfer Coefficients for Supersonic Open Cavity Flow," Journal of Heat Transfer, 1969, pp. 168-170.

${ }^{32}$ Netterfield, M. and Hillier, R.: "Experiment and Computation in Hypersonic Cavity Flows," AIAA Paper 89-1842, Presented at $20^{\text {th }}$ Fluid Dynamics, Plasma Dynamics and Lasers Conference, Buffalo, NY, June 12-14, 1989.

${ }_{33}$ Thomann, H: "Measurment of Heat Transfer and Recovery Temperature in Regions of Separated Flow at a Mach Number of 1.8," FFA, Rpt 82, 1959.

${ }^{34}$ Hahn, Mansop: "Experimental Investigation of Separated Flows over a Cavity at Hypersonic Speed," AIAA No. 68-672, AIAA Journal, Vol. 7, No. 6, June 1969, pp. 1092-1098.

${ }^{35}$ Nestler, D.E., Saydah, A.R., and Auxer, W.L.: "Heat Transfer to Steps and Cavities in Hypersonic Turbulent Flow," AIAA Paper No. 68-673, Presented at Fluid and Plasma Dynamics Conference, Los Angeles, Calif., 1968.

${ }^{36}$ White, F. M.: "Viscous Fluid Flow", First Edition, McGraw-Hill Book Company, 1974. 
Tables

Table 1.- Turbulent test matrix for 20-Inch Mach 6 Tunnel Test 6888.

\begin{tabular}{|c|c|c|c|c|c|c|c|c|c|c|c|c|c|c|}
\hline$\Xi$ & ن̊ & $\underbrace{\stackrel{0}{0}}_{0}$ & $\frac{\mathbf{R e}}{\mathbf{L}}$ & 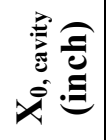 & $\mathbf{M}_{\mathbf{e}}$ & $\operatorname{Re}_{\theta}$ & $\frac{\mathbf{R e}_{\theta}}{\mathbf{M}_{\mathbf{e}}}$ & 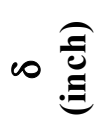 & $\frac{\mathbf{H}}{\delta}$ & $\frac{\mathbf{W}}{\mathbf{H}}$ & $\frac{\mathbf{L}}{\mathbf{H}}$ & $\frac{\mathbf{L}}{\delta}$ & $\frac{0}{4}$ & $\sum_{x}^{\frac{x}{x}}$ \\
\hline 39 & $27 b$ & 0 & 2.0 & 10.5 & 2.93 & 123 & 42 & 0.248 & - & - & - & - & - & - \\
\hline 31 & $27 \mathrm{~b}$ & 0 & 4.0 & 18 & 2.93 & 150 & 50 & 0.312 & - & - & - & - & - & - \\
\hline 42 & $27 \mathrm{~b}$ & -10 & 2.0 & 10.5 & 2.31 & 155 & 67 & 0.178 & - & - & - & - & - & - \\
\hline 226 & - & -5 & 0.6 & 10.5 & 2.63 & 97 & 37 & 0.299 & - & - & - & - & - & - \\
\hline 215 & - & -5 & 1.9 & 10.5 & 2.62 & 135 & 51 & 0.216 & - & - & - & - & - & - \\
\hline 117 & 28 & 0 & 2.0 & 10.5 & 2.93 & 123 & 42 & 0.248 & 0.585 & 2.6 & 15.6 & 9.1 & 1.143 & 5.454 \\
\hline 95 & 29 & 0 & 2.0 & 10.5 & 2.93 & 123 & 42 & 0.248 & 0.612 & 2.5 & 18.1 & 11.1 & 0.895 & 5.084 \\
\hline 67 & 30 & 0 & 2.0 & 10.5 & 2.93 & 123 & 42 & 0.248 & 0.626 & 2.5 & 20.8 & 13.0 & 1.007 & 5.479 \\
\hline 87 & 31 & 0 & 2.0 & 10.5 & 2.93 & 123 & 42 & 0.248 & 0.618 & 2.5 & 26.5 & 16.4 & 0.945 & 4.668 \\
\hline 108 & 32 & 0 & 2.0 & 10.5 & 2.93 & 123 & 42 & 0.248 & 0.578 & 2.6 & 34.0 & 19.7 & 0.791 & 4.939 \\
\hline 139 & 36 & 0 & 2.0 & 10.5 & 2.93 & 123 & 42 & 0.248 & 1.389 & 2.4 & 14.3 & 19.8 & 1.264 & 8.425 \\
\hline 140 & 37 & 0 & 2.0 & 10.5 & 2.93 & 123 & 42 & 0.248 & 1.321 & 2.6 & 18.2 & 24.1 & 1.249 & 5.741 \\
\hline 141 & 38 & 0 & 2.0 & 10.5 & 2.93 & 123 & 42 & 0.248 & 1.386 & 2.4 & 20.5 & 28.4 & 1.188 & 8.270 \\
\hline 142 & 39 & 0 & 2.0 & 10.5 & 2.93 & 123 & 42 & 0.248 & 1.354 & 2.5 & 26.2 & 35.5 & 0.999 & 8.446 \\
\hline 143 & 40 & 0 & 2.0 & 10.5 & 2.93 & 123 & 42 & 0.248 & 1.404 & 2.4 & 30.5 & 42.8 & 0.923 & 6.378 \\
\hline 132 & 41 & 0 & 4.0 & 18 & 2.99 & 150 & 50 & 0.312 & 0.535 & 2.1 & 12.8 & 6.8 & 1.311 & 5.585 \\
\hline 134 & 42 & 0 & 4.0 & 18 & 2.99 & 150 & 50 & 0.312 & 0.458 & 2.5 & 17.9 & 8.2 & 1.325 & 4.754 \\
\hline 137 & 43 & 0 & 4.0 & 18 & 2.99 & 150 & 50 & 0.312 & 0.474 & 2.4 & 20.6 & 9.8 & 1.380 & 4.550 \\
\hline 138 & 44 & 0 & 4.0 & 18 & 2.99 & 150 & 50 & 0.312 & 0.459 & 2.5 & 26.5 & 12.1 & 1.267 & 5.990 \\
\hline 144 & 48 & 0 & 4.0 & 18 & 2.99 & 150 & 50 & 0.312 & 1.069 & 2.4 & 13.8 & 14.8 & 1.710 & 7.509 \\
\hline 148 & 49 & 0 & 4.0 & 18 & 2.99 & 150 & 50 & 0.312 & 1.106 & 2.3 & 16.3 & 18.0 & 1.410 & 6.019 \\
\hline 147 & 50 & 0 & 4.0 & 18 & 2.99 & 150 & 50 & 0.312 & 1.111 & 2.3 & 19.1 & 21.2 & 1.421 & 10.956 \\
\hline 214 & 28 & -5 & 1.9 & 10.5 & 2.62 & 135 & 51 & 0.216 & 0.671 & 2.6 & 15.6 & 10.5 & 1.110 & 4.595 \\
\hline 215 & 29 & -5 & 1.9 & 10.5 & 2.62 & 135 & 51 & 0.216 & 0.701 & 2.5 & 18.1 & 12.7 & 1.058 & 3.727 \\
\hline 219 & 31 & -5 & 1.9 & 10.5 & 2.62 & 135 & 51 & 0.216 & 0.709 & 2.5 & 26.5 & 18.8 & 1.047 & 3.370 \\
\hline 222 & 32 & -5 & 1.9 & 10.5 & 2.62 & 135 & 51 & 0.216 & 0.663 & 2.6 & 34.0 & 22.5 & 1.000 & 3.726 \\
\hline 116 & 28 & -10 & 2.0 & 10.5 & 2.31 & 155 & 67 & 0.178 & 0.814 & 2.6 & 15.6 & 12.7 & 1.210 & 4.130 \\
\hline 76 & 72 & -10 & 2.0 & 10.5 & 2.31 & 155 & 67 & 0.178 & 0.813 & 7.9 & 20.0 & 16.3 & 0.808 & 2.449 \\
\hline 94 & 29 & -10 & 2.0 & 10.5 & 2.31 & 155 & 67 & 0.178 & 0.851 & 2.5 & 18.1 & 15.4 & 1.057 & 3.778 \\
\hline 66 & 30 & -10 & 2.0 & 10.5 & 2.31 & 155 & 67 & 0.178 & 0.871 & 2.5 & 20.8 & 18.1 & 1.127 & 4.780 \\
\hline 85 & 31 & -10 & 2.0 & 10.5 & 2.31 & 155 & 67 & 0.178 & 0.860 & 2.5 & 26.5 & 22.8 & 1.038 & 3.608 \\
\hline 107 & 32 & -10 & 2.0 & 10.5 & 2.31 & 155 & 67 & 0.178 & 0.805 & 2.6 & 34.0 & 27.3 & 1.008 & 4.248 \\
\hline 226 & 30 & -5 & 0.6 & 10.5 & 2.65 & 99 & 37 & 0.299 & 0.518 & 2.4 & 20.8 & 10.8 & 0.917 & 2.727 \\
\hline
\end{tabular}


Table 2.- Laminar cavity correlation coefficient powers derived from Mach 6 baseline data.

\begin{tabular}{|l|l|l|}
\cline { 2 - 3 } Power & BF $_{\text {AVG }}$ & BF $_{\text {MAX }}$ \\
\hline$\alpha$ & 3.30 & 3.30 \\
\hline$\beta$ & 2.70 & 3.70 \\
\hline$\sigma$ & 0.00 & 0.20 \\
\hline$\tau$ & 0.10 & 0.05 \\
\hline
\end{tabular}

Table 3.- Laminar cavity correlation coefficient values for $y=a+b x$ fit of Mach 6 baseline data.

\begin{tabular}{|c|ccc|ccc|}
\cline { 2 - 7 } \multicolumn{1}{c|}{} & \multicolumn{3}{c|}{ BF $_{\text {AvG }}$} & \multicolumn{3}{c|}{ BF $_{\text {MAX }}$} \\
\hline Correlation & -2.8251 & 2.9650 & 0.9882 & -0.6305 & 3.8695 & 0.9895 \\
$\mathbf{9 9 \%}$ UCL & -2.1834 & 2.9715 & & 0.1707 & 3.8737 & \\
$\mathbf{9 9 \%}$ UPL & -2.7237 & 2.9540 & & -0.5137 & 3.8588 & \\
\hline
\end{tabular}

Table 4.- Turbulent cavity correlation coefficient powers.

\begin{tabular}{|l|l|l|}
\hline Power & $\mathbf{B F}_{\mathbf{A V G}}$ & $\mathbf{B F}_{\mathbf{M A X}}$ \\
\hline$\alpha$ & 2.65 & 3.40 \\
\hline$\beta$ & 3.20 & 4.20 \\
\hline$\sigma$ & 0.25 & 0.80 \\
\hline$\tau$ & 0.35 & 0.40 \\
\hline
\end{tabular}

Table 5.- Turbulent cavity correlation coefficient values for $y=a+b x$ fit of Mach 6 baseline data.

\begin{tabular}{|c|c|c|c|c|c|c|}
\hline & \multicolumn{3}{|c|}{$\overline{\mathrm{BF}_{\mathrm{AVG}}}$} & \multicolumn{3}{|c|}{$\overline{\text { BF }_{\text {MAX }}}$} \\
\hline & $\mathbf{a}$ & b & DF Adj $R^{2}$ & $\mathbf{a}$ & b & DF Adj $R^{2}$ \\
\hline Correlation & -3.8686 & 2.7683 & 0.9925 & -8.4946 & 3.9942 & 0.9879 \\
\hline 99\% UCL & -3.4116 & 2.8636 & & -7.1230 & 4.2394 & \\
\hline 99\% UPL & -3.5717 & 2.7711 & & -7.9645 & 4.0036 & \\
\hline
\end{tabular}


Table 6.- Archival cavity-floor heating data, geometry, and conditions.

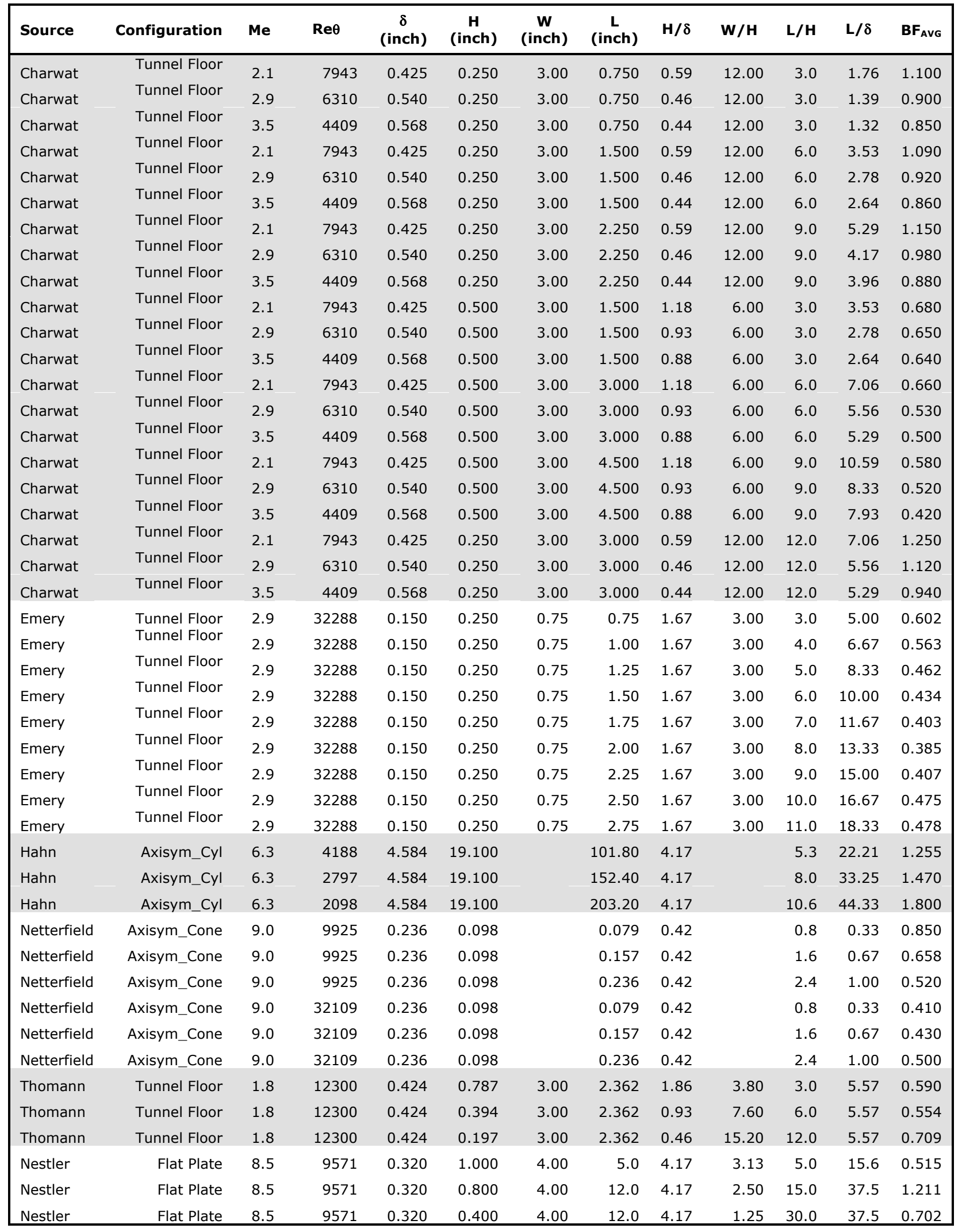


Table 7.- Turbulent open cavity correlation coefficient powers.

\begin{tabular}{|c|c|}
\hline Power & BF $_{\text {AVG }}$ \\
\hline$\alpha$ & 3.30 \\
\hline$\beta$ & 2.70 \\
\hline$\sigma$ & 0.00 \\
\hline$\tau$ & 0.10 \\
\hline
\end{tabular}

Table 8.- Turbulent open-cavity correlation coefficient values for $y=a+b x$ fit of archival data.

\begin{tabular}{|c|cccc|}
\cline { 2 - 5 } \multicolumn{1}{c|}{} & \multicolumn{4}{c|}{ BF $_{\text {AVG }}$} \\
\cline { 2 - 5 } \multicolumn{1}{c|}{} & $\mathbf{a}$ & $\mathbf{b}$ & $\mathbf{c}$ & $\begin{array}{c}\text { DF Adj } \\
\mathbf{R}^{\mathbf{2}}\end{array}$ \\
\hline Correlation & -2.3741 & 2.6034 & 0.0000 & 0.9752 \\
$\mathbf{9 9 \%}$ UCL & -1.8950 & 2.3604 & 0.0538 & \\
$\mathbf{9 9 \%}$ UPL & -1.0967 & 2.5399 & 0.0139 & \\
\hline
\end{tabular}

\section{Figures}

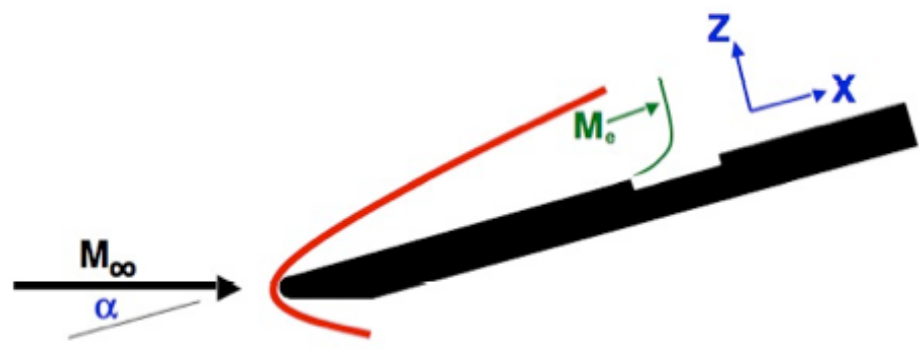

Figure 1. Model coordinate system.

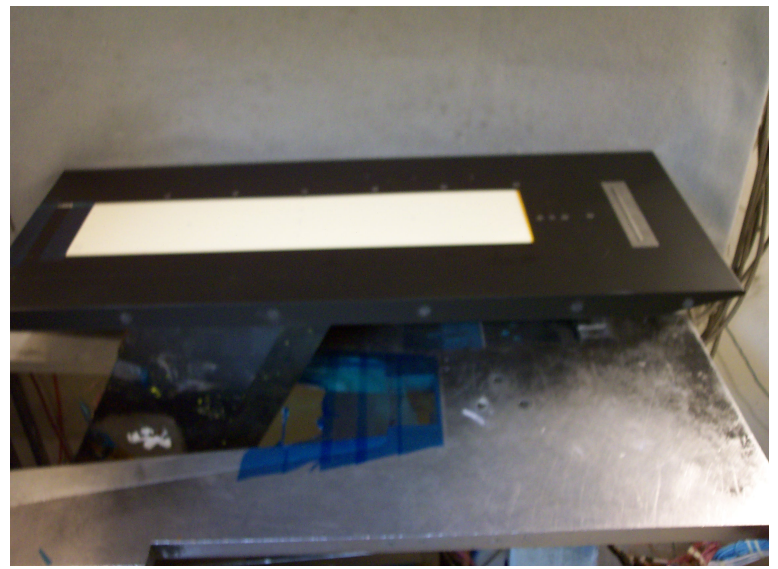

Figure 2. Baseline model with 4-inch by 18-inch ceramic inserts used in Mach 6 for T6888.

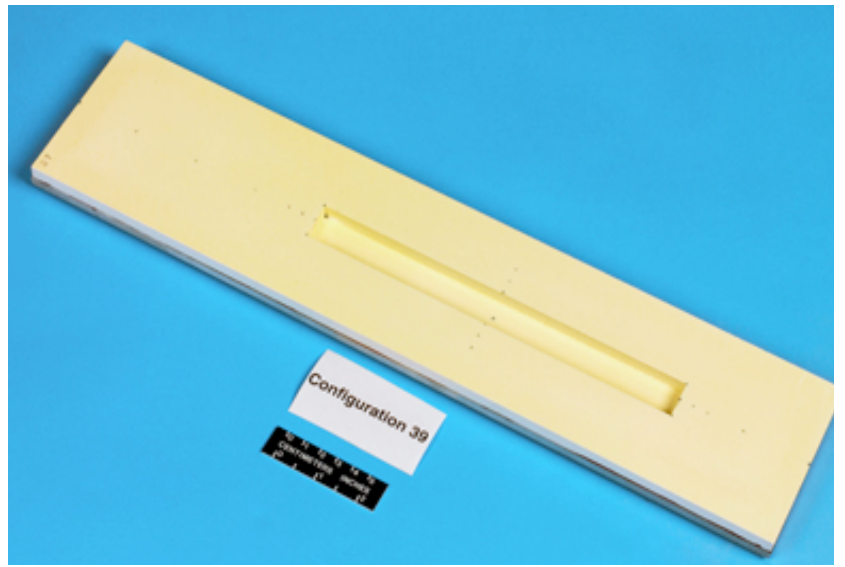

Figure 3. Sample cavity insert model used in Mach 6 for T6888. 


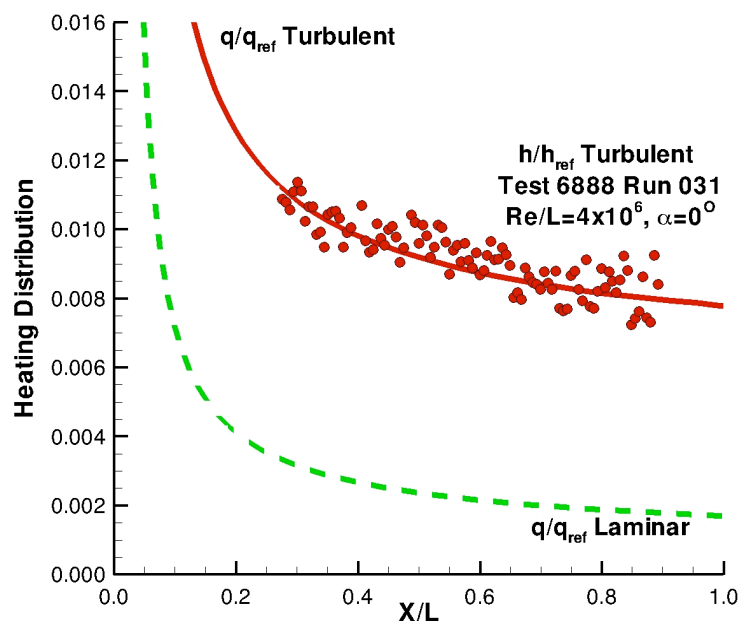

(a) Computational and experimental heating distributions.

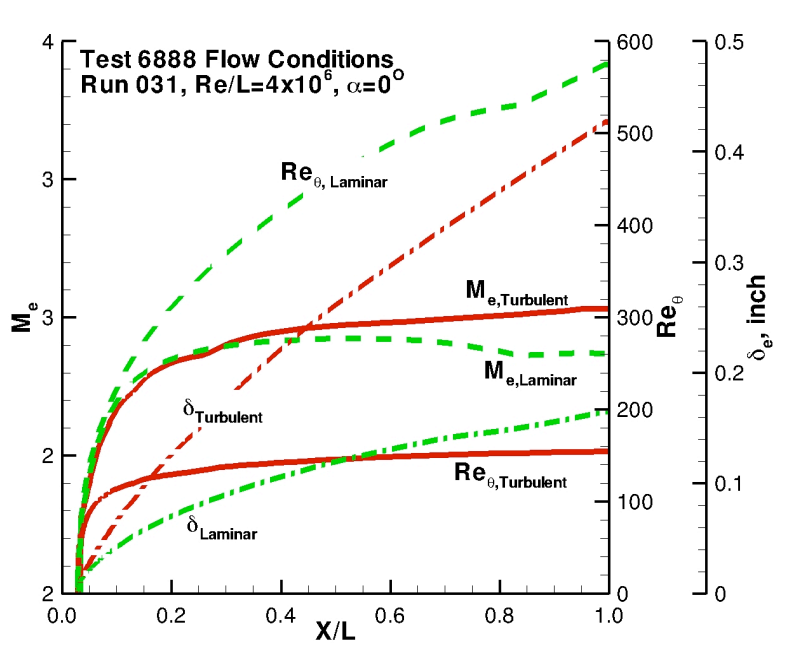

(b) Surface flow properties.

Figure 4.- Turbulent CFD simulations for Test 6888 Run 31.

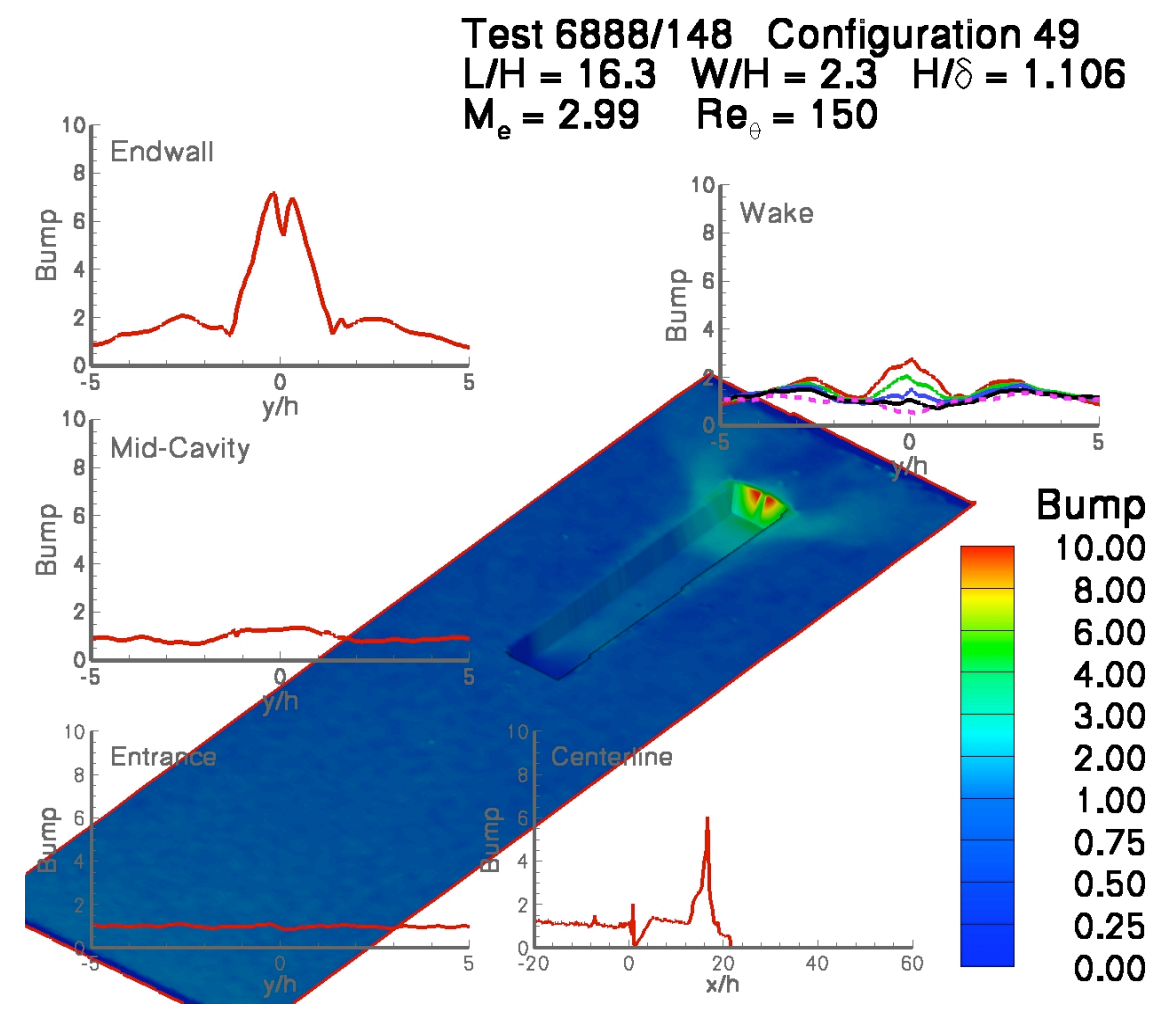

Figure 5.- Effect of length variation for $M_{e}=2.99, R_{\theta}=150, H / \delta=1.1-L / H \approx 16$. 


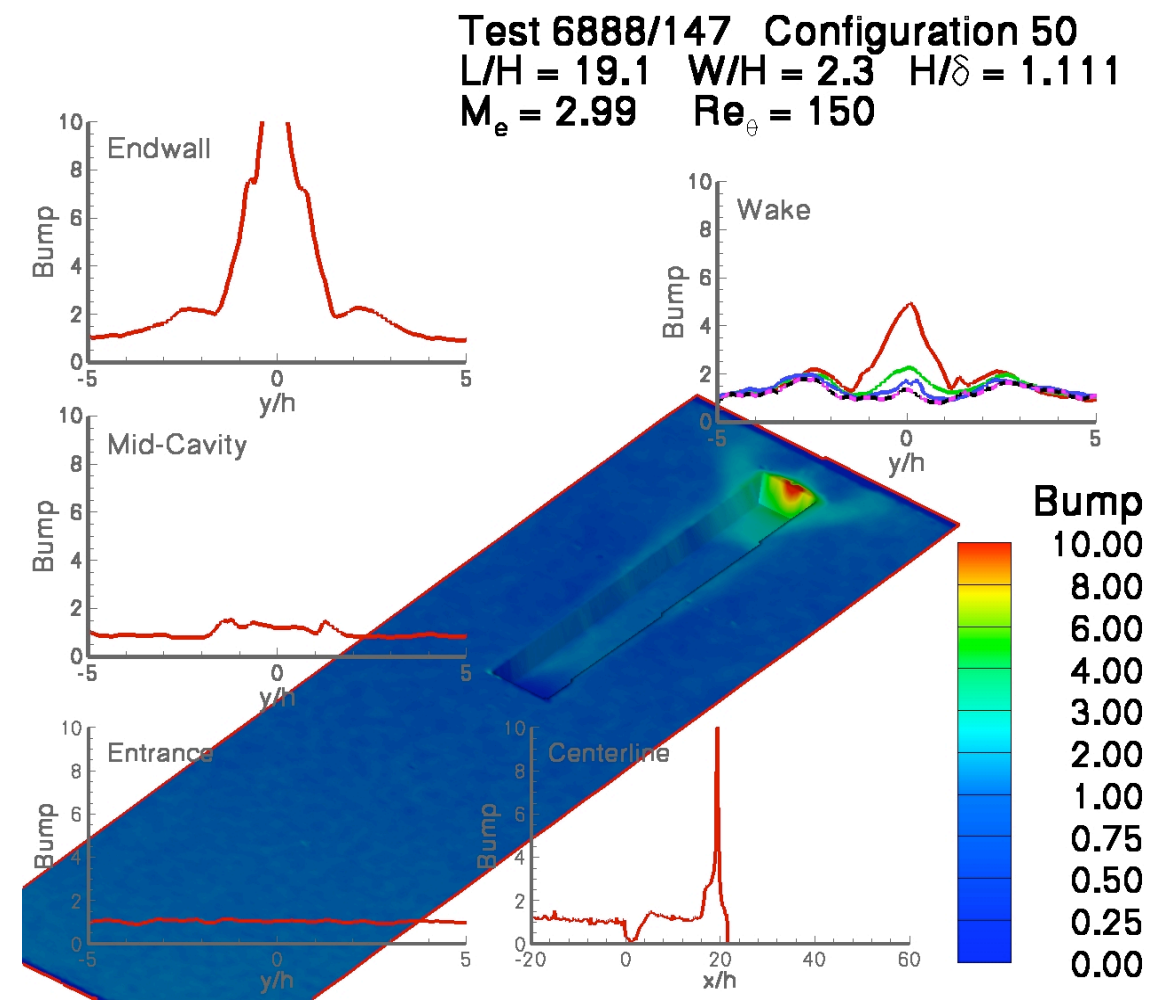

Figure 6.- Effect of length variation for $M_{e}=2.99, \operatorname{Re}_{\theta}=150$, and $H / \delta=1.1-L / H \approx 19$.

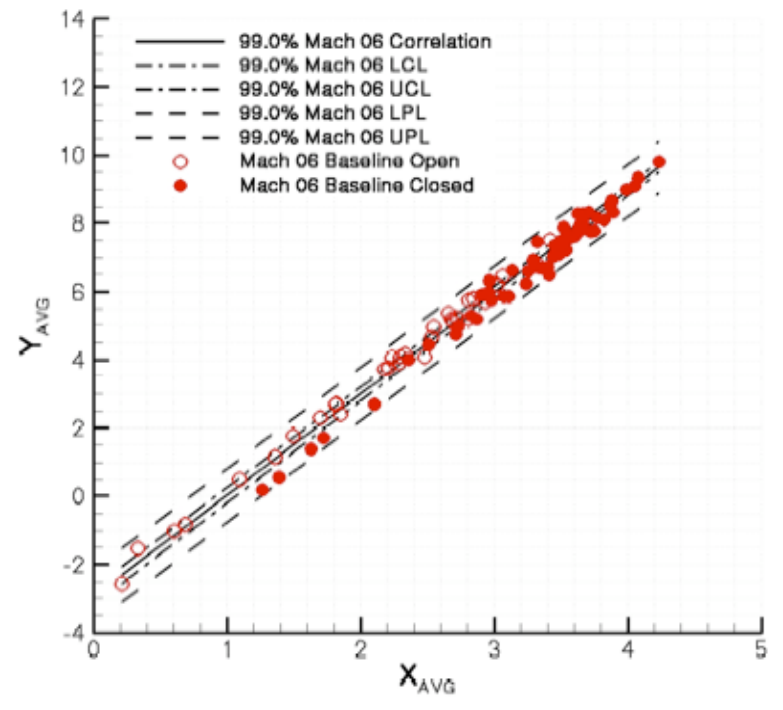

a) Cavity floor correlation.

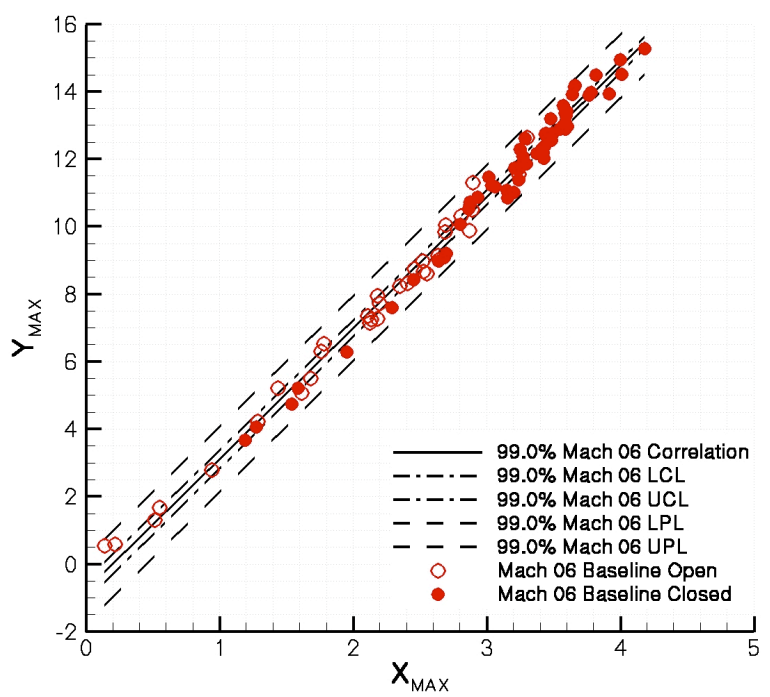

b) Cavity endwall maximum correlation.

Figure 7.- Laminar baseline Mach 6 correlation. 

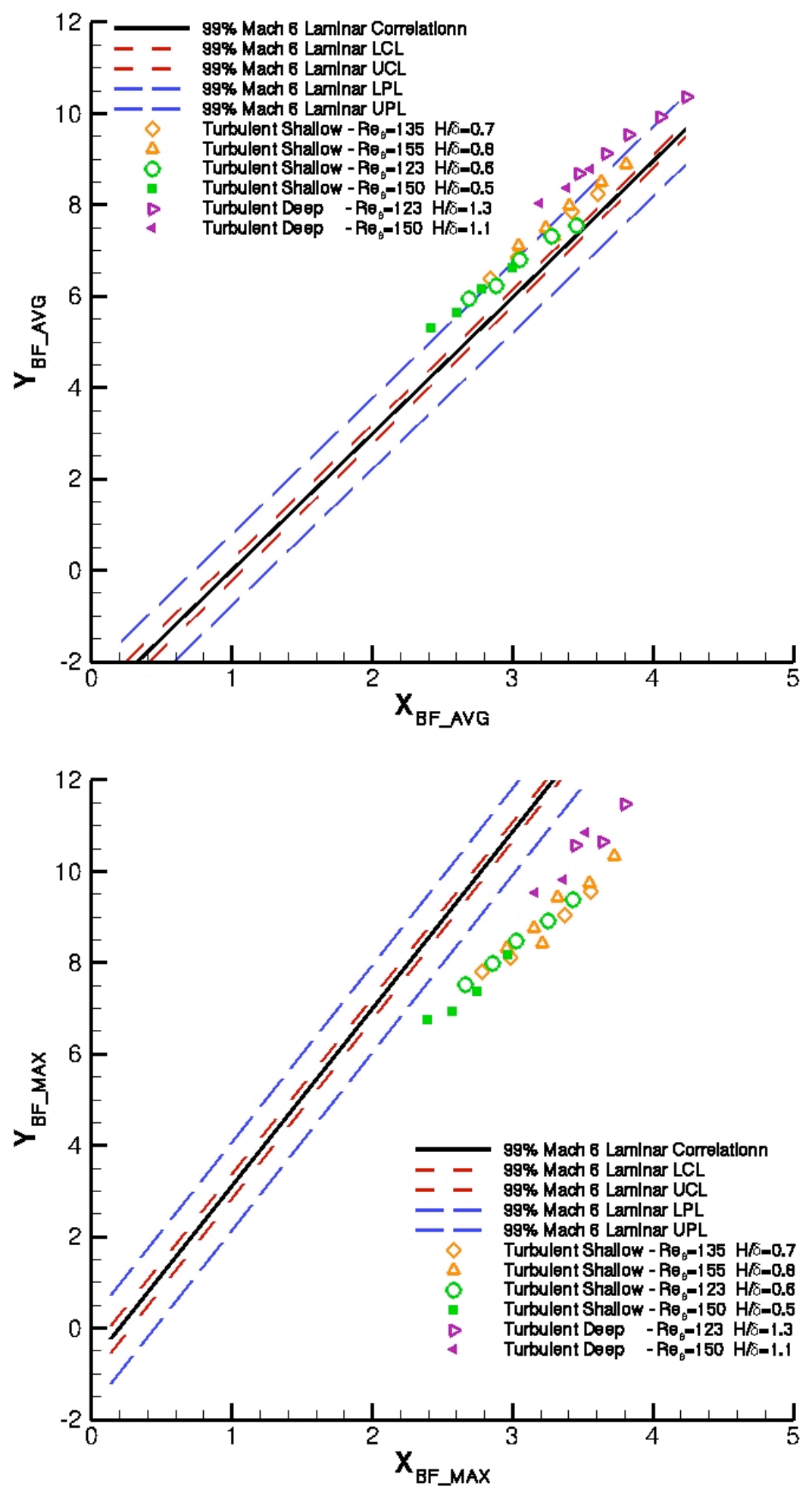

Figure 8.- Correlation of turbulent data with laminar correlation coefficients. 

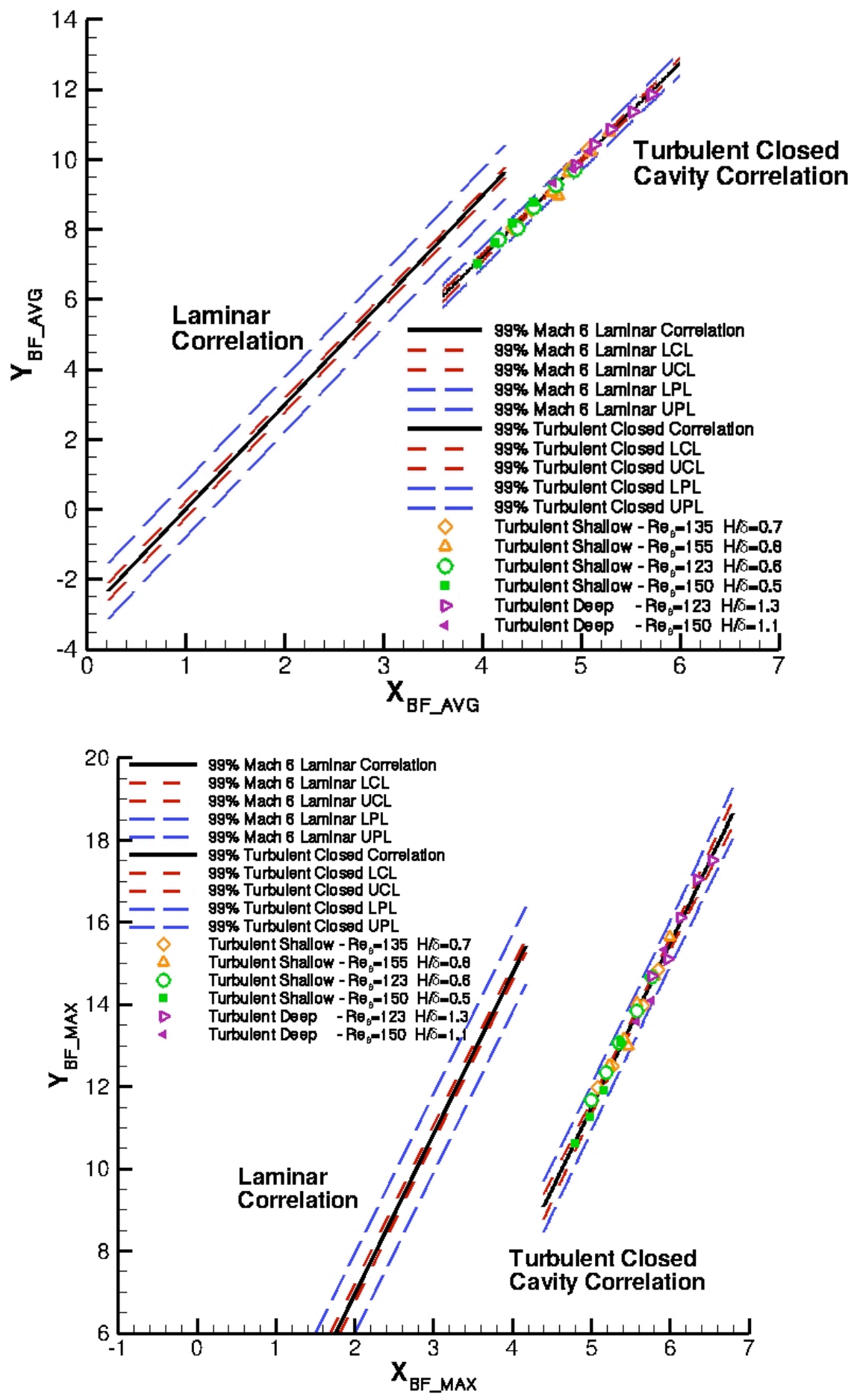

Figure 9.- Correlation of turbulent data with turbulent correlation coefficients, including $99 \%$ uncertainty analysis. 


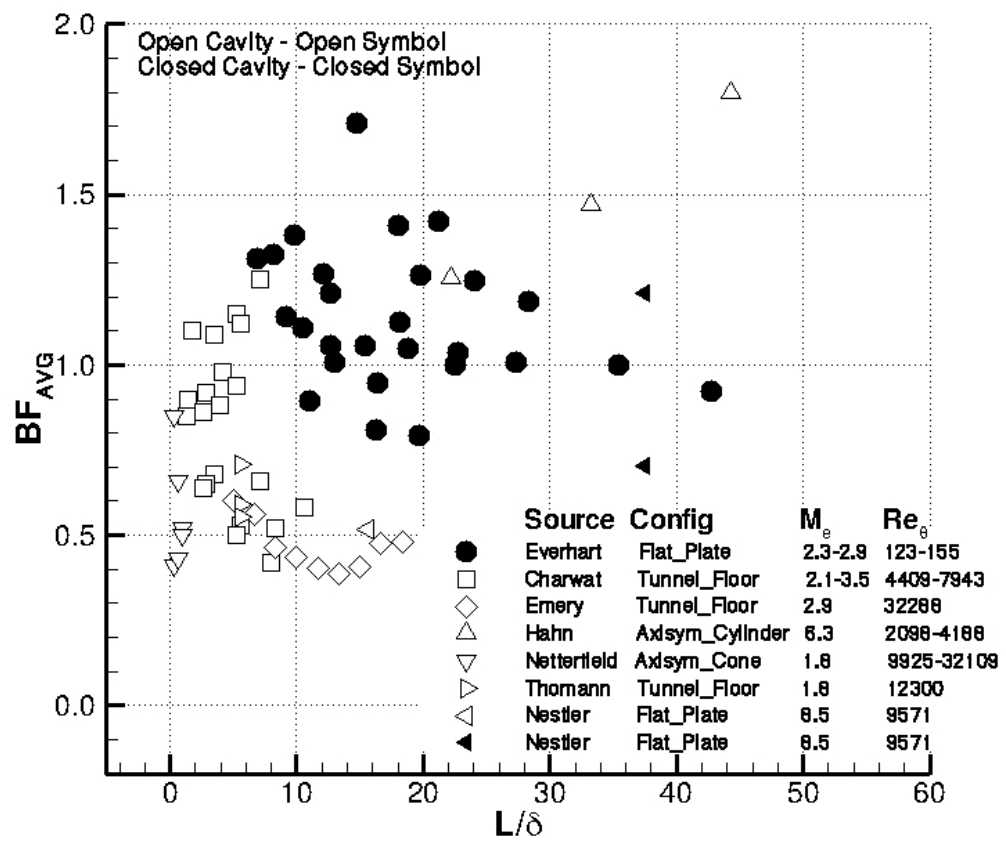

Figure 10.- Archival turbulent-entry open-cavity floor-averaged heating augmentation data.

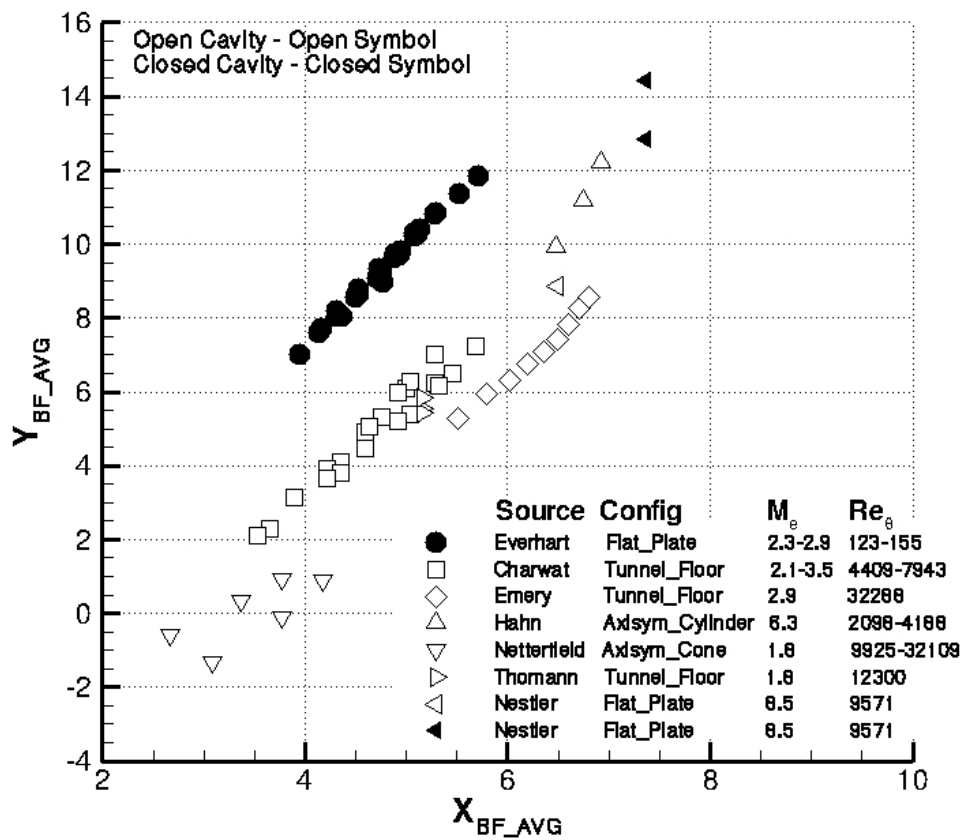

Figure 11.- Turbulent-entry open-cavity floor-heating data scaled using turbulent closed-cavity correlation. 


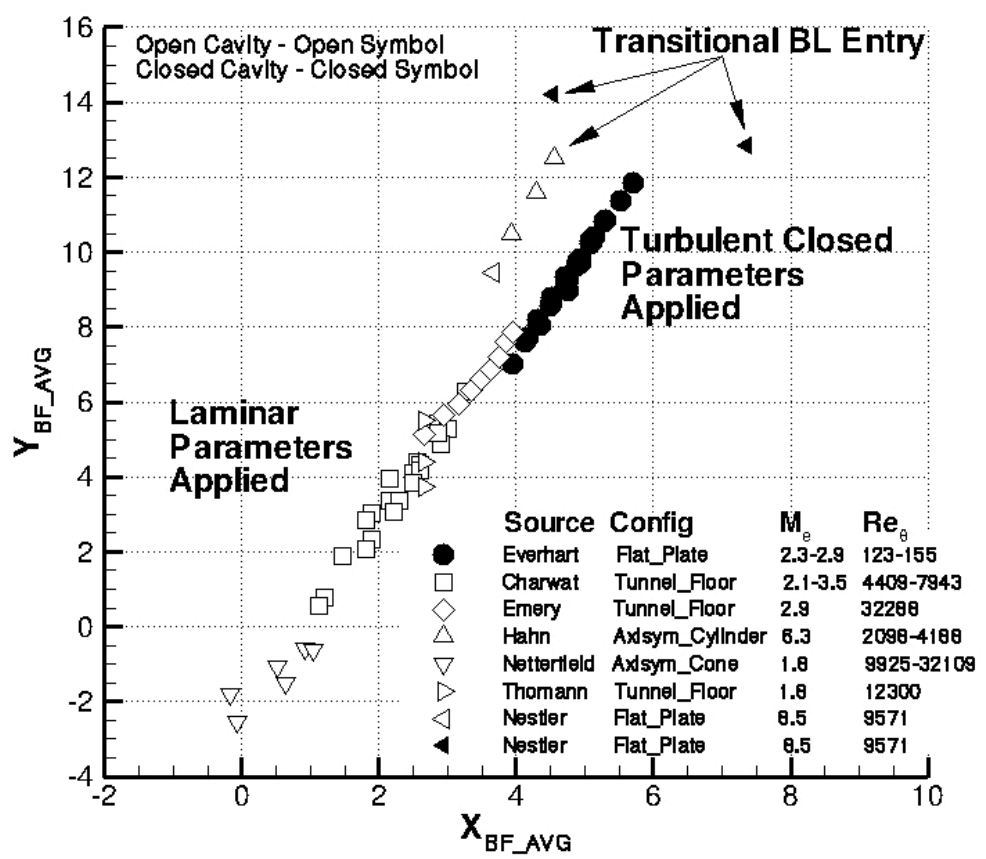

Figure 12.- Correlated turbulent cavity-floor-averaged heating augmentation.

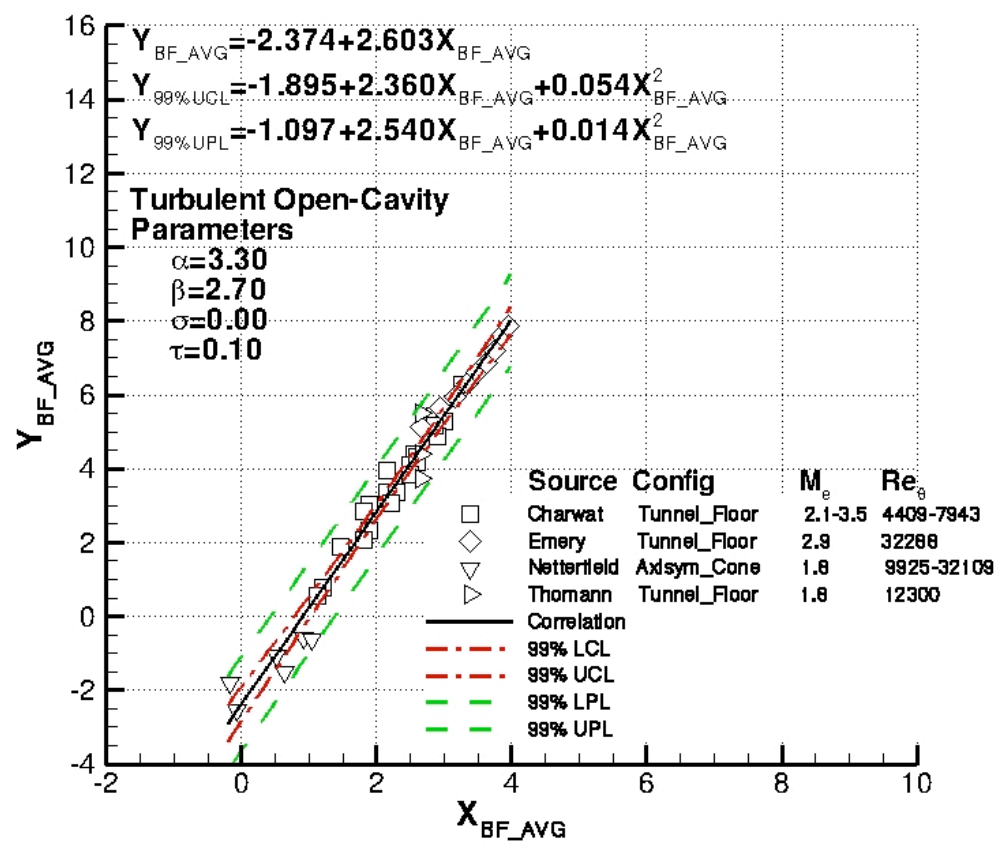

Figure 13.- Turbulent open-cavity floor-averaged heating augmentation. 